\title{
LA-UR-21-22392
}

Approved for public release; distribution is unlimited.

Title:

DDSTE Lab Overview March 2021

Author(s): $\quad$ Sarrao, John Louis

Intended for: General use for ALDs and DDSTE.

Issued: 
Disclaimer:

Los Alamos National Laboratory, an affirmative action/equal opportunity employer, is operated by Triad National Security, LLC for the National Nuclear Security Administration of U.S. Department of Energy under contract 89233218CNA000001. By approving this article, the publisher recognizes that the U.S. Government retains nonexclusive, royalty-free license to publish or reproduce the published form of this contribution, or to allow others to do so, for U.S. Government purposes. Los Alamos National Laboratory requests that the publisher identify this article as work performed under the auspices of the U.S. Department of Energy. Los Alamos National Laboratory strongly supports academic freedom and a researcher's right to publish; as an institution, however, the Laboratory does not endorse the viewpoint of a publication or guarantee its technical correctness. 


\section{Los Alamos NATIONAL LABORATORY}

\section{Welcome to Los Alamos National Laboratory Overview}

March 2021 
Our national security mission is broad and important

- Ensure the safety, reliability, and performance of the U.S nuclear stockpile

- Serve as design agency for 4 of 7 nation's deployed nuclear weapons systems

- Fulfill production agency roles

- Anticipate, reduce, and response to emerging national security threats

- Deliver scientific discovery and technical breakthroughs

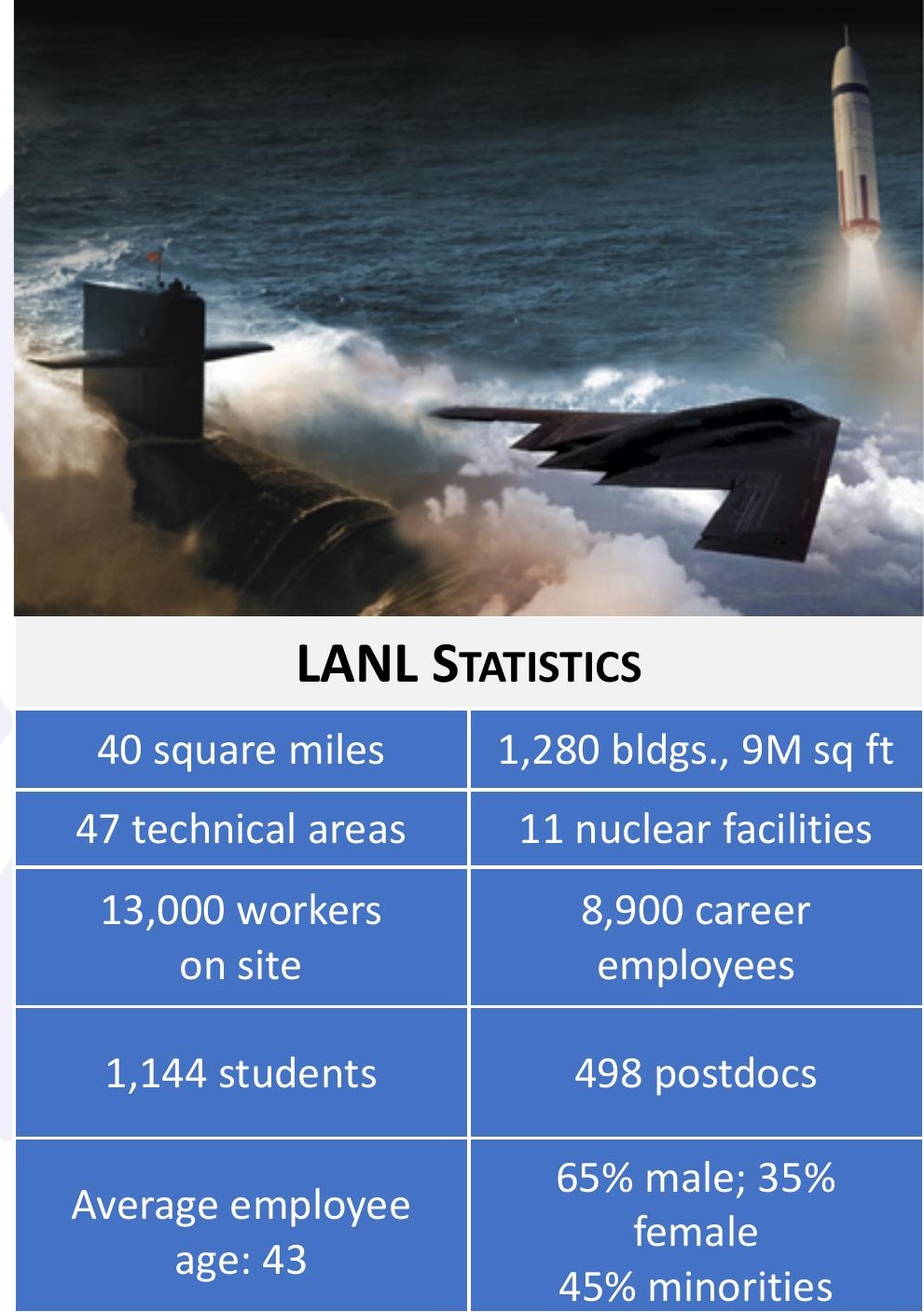




\section{LANL Organization structure}

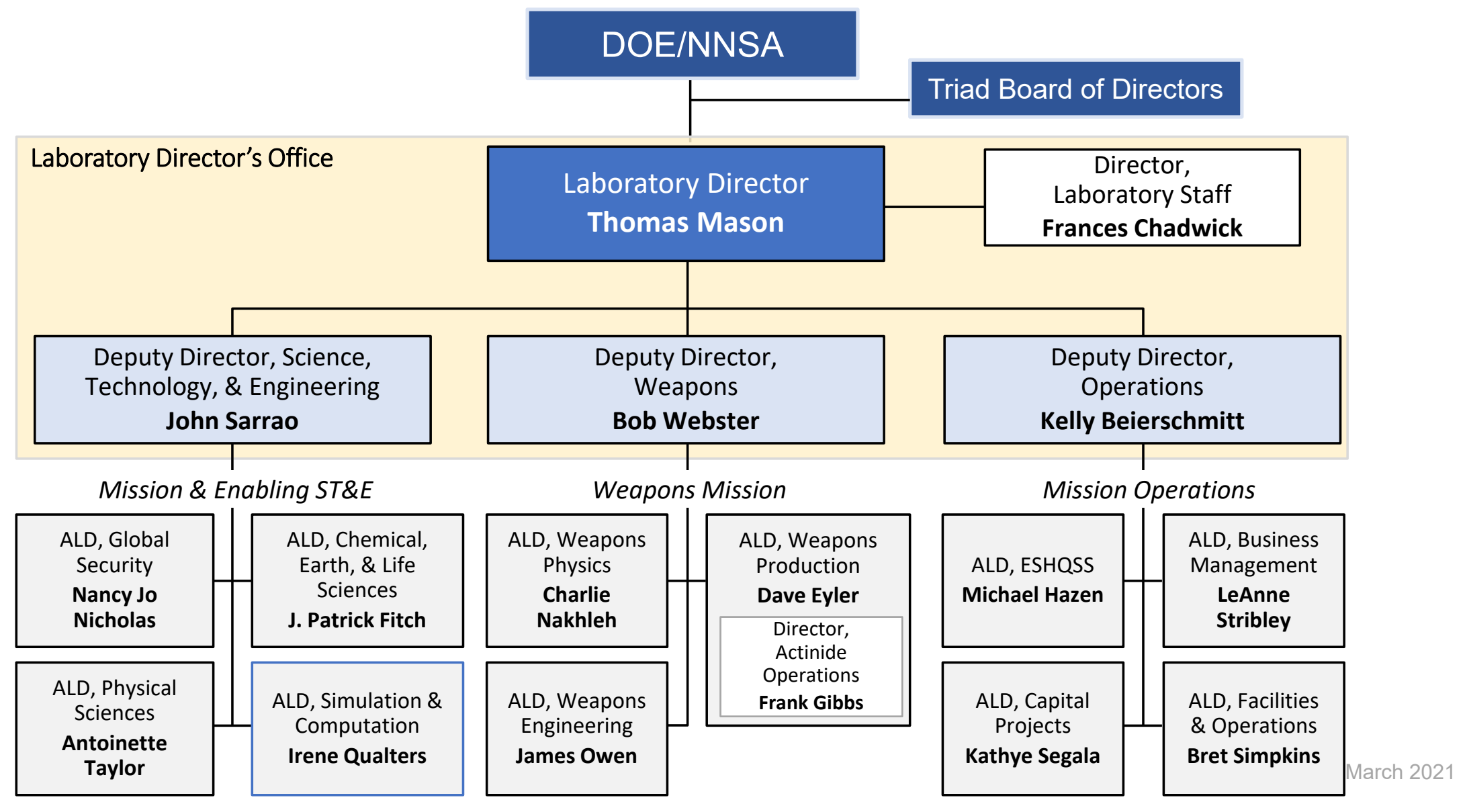




\section{The DDSTE organization facilitates capability stewardship}

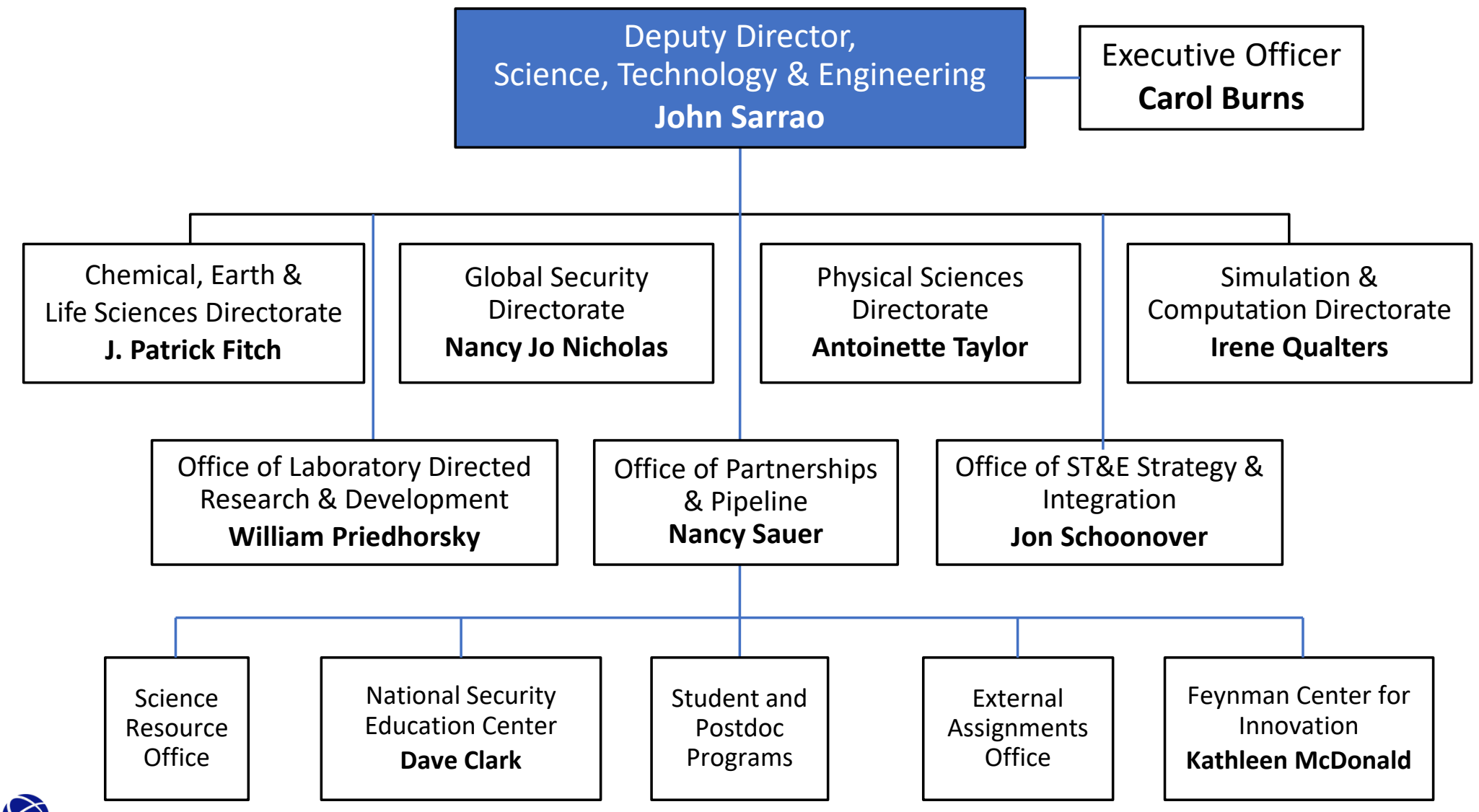




\section{Simultaneous excellence:}

\section{Balance between operations and mission}

Design, produce, and certify current and future nuclear weapons and reduce global nuclear threats

ar

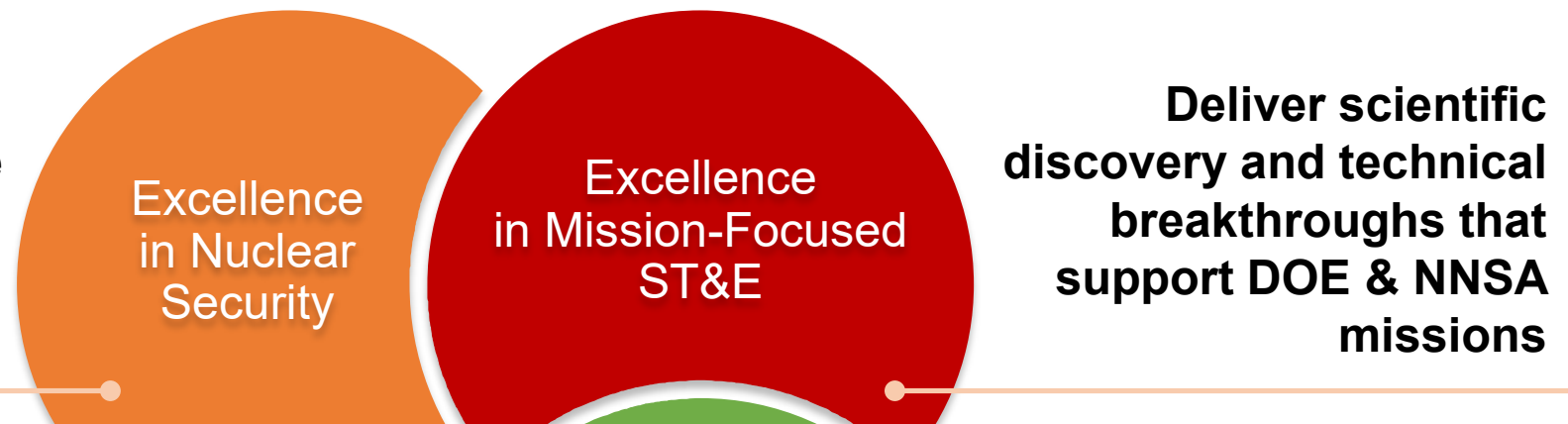

Execute sustained operations that are reliable and responsive to mission needs

\section{ture}

rand

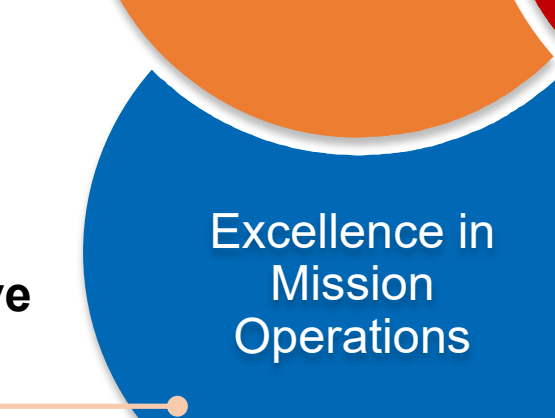
sion-Focused
ST\&E


Our capability pillars define six key areas of science, technology, and engineering in which we must lead
MATERIALS FOR THE FUTURE

NuClear AND PARTICle

FUTURES

INTEGRATING INFORMATION,

SCIENCE, AND TECHNOLOGY

FOR PREDICTION

SCIENCE OF SignatURES

COMPLEX NATURAL AND

ENGINEERED SYSTEMS
Defects and Interfaces

Extreme Environments

Emergent Phenomena

Applied Nuclear Science \& Engineering

Nuclear \& Particle Physics, Astrophysics \& Cosmology

Accelerator Science \& Technology

High Energy Density Physics \& Fluid Dynamics

Computing Platforms

Computational Methods

Data Science

Nuclear Detonation

Nuclear Processing, Movement, Weaponization

Natural and Anthropogenic Phenomena

Human-Natural System Interactions: Nuclear

Engineered Systems

Human-Natural System Interactions: Non-Nuclear

Design

WEAPONS SYSTEMS
Manufacturing

Analysis 


\section{FY21 Lab Agenda}

\section{SIMULTANEOUS EXCELLENCE}

Strategic

Objective

(10-20 years)

Critical

Outcomes

(5-10 years)

Major Strategic Initiatives

(1-5 years)

1.0
NUCLEAR SECURITY

\section{Excellence in \\ Nuclear Security}

Design, produce, and certify current and future nuclear weapons and reduce global nuclear threats

1.1 Execute LANL's Manufacturing mission to deliver 30 plutonium pits per year

1.2 Transform nuclear weapons warhead design and production

1.3 Anticipate threats to global security; develop and deploy revolutionary tools to detect, deter, and respond

1.4 Support modernization of LANL warhead systems

1.5. Assess the stockpile as it ages and project weapon systems lifetimes

\section{0}

MisSION-FOCUSEd SCIENCE, TeCHNOLOGY \& ENGINEERING

Excellence in Mission-Focused Science, Technology \& Engineering

Deliver scientific discovery and technical breakthroughs that support DOE and NNSA missions

2.1 Refresh and refine the LANL capability pillar framework

2.2 Advance accelerator science, engineering, and technology to enable future stewardship capabilities

2.3 Advance the frontiers of computing to exascale and beyond

2.4 Assert leadership in the national quantum initiative

2.5 Develop and implement an integrated nuclear energy and nuclear materials initiative

2.6 Implement an integrated initiative for plutonium and actinide missions based on FY2O strategy

2.7 Implement a national security life sciences initiative

\section{0}

Mission Operations

\section{Excellence in}

\section{Mission Operations}

Execute sustained operations that are reliable and responsive to mission needs

3.1 Change organizational culture with an emphasis on organizational learning

3.2 Improve integrated planning across priority mission activities and infrastructure

3.3 Address critical issues related to NMCA, nuclear safety, criticality safety, waste, and classified enhancements

3.4 Implement systematic process improvement to drive increased rigor and efficiency in work execution

3.5 Enhance quality of work life, workforce planning, and training and development
4.0

COMMUNITY RELATIONS

Excellence in

Community Relations

Sustain and enhance LANL's partnership with the community across the Northern New Mexico region

4.1 Continue commitment to the community with educational, economic, and philanthropic investments of time and resources

4.2 Strengthen pipelines and partnerships to build workforce of the future

4.3 Enhance small business participation in executing LANL scope across all directorates

4.4 Demonstrate agility and flexibility in our partnerships, effectively balancing benefit and risks 
The strength of our capabilities allows us to engage in multi-institutional consortia

National Risk Assessment Partnership (NRAP)

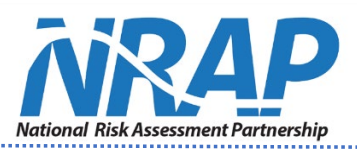

Producing Algae for Coproducts and Energy (PACE)

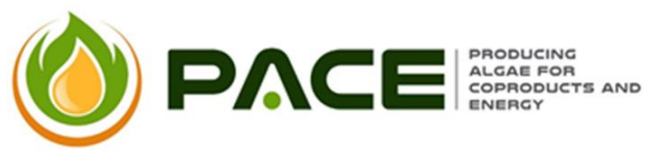

Fuel Cell Performance and Durability (FC-PAD)

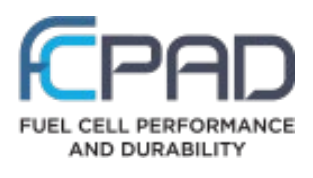

Carbon Capture Simulation for Industry Impact (CCSI $\left.{ }^{2}\right)$

$$
-\infty 0^{8} \mathrm{CCSI}^{2}
$$

Algal Biomass Yield (ABY)

@ Kona Demonstration Facility (KDF)

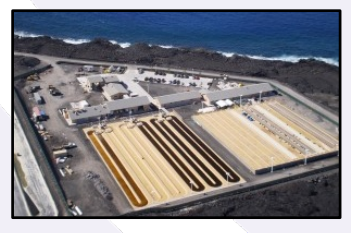

Grid Modernization Laboratory Consortium (GMLC)

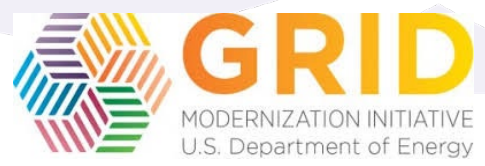




\section{Partnerships \& Pipeline Office (PPO) was formed to enhance our internal coordination and external outreach}

Pipeline Mechanisms:

- Student Programs: Education opportunities for high school, undergraduate, and graduate students

- Postdoctoral Programs: Postdocs contribute to research efforts, enhance our STE capabilities

Partnership Opportunities:

- National Security Education Center Strategic Centers:

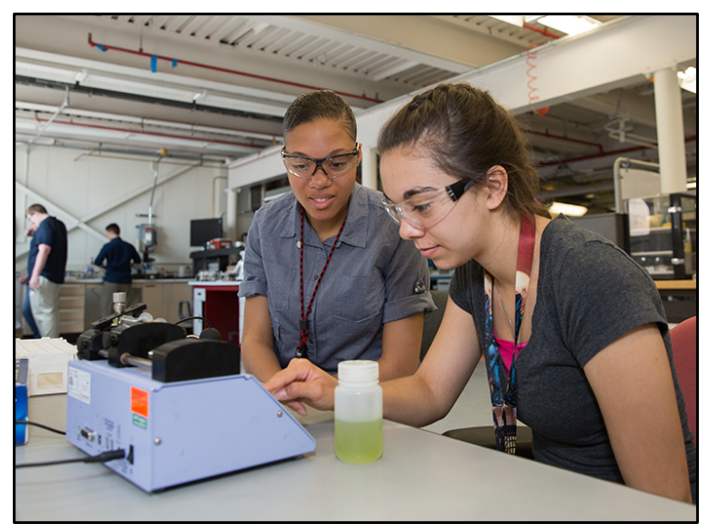
Scientific centers of excellence with high international visibility that innovate strategic new science and education programs

- New Mexico Consortium Coordination: Creative mechanisms for collaboration with NM research universities through joint appointments and unique facilities

- Feynman Center for Innovation: From "tech transfer"' to innovation asset stewardship with strategy driven through Innovation Asset Strategic Council 
We have a new administration in Washington, D.C.

- Much has changed in D.C. over the last few months

- Granholm confirmed as Secretary of Energy

- We have a new acting NNSA Administrator

- The Laboratory's priorities \& mission will endure

- We see new opportunities in climate research, nonproliferation, renewable energy, and bioscience
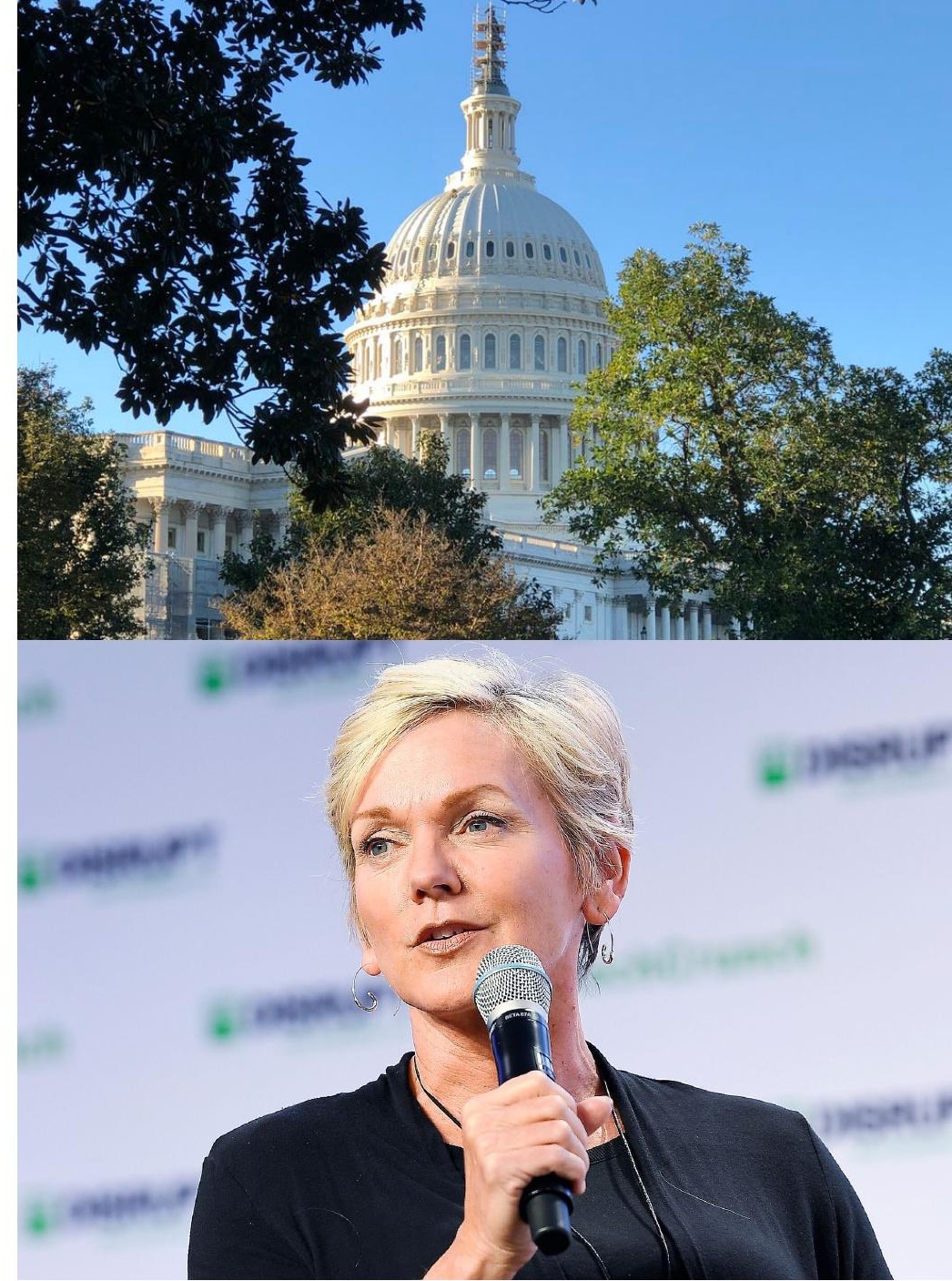


\section{Pipeline and diversity initiatives}

\section{essential to our success}

- Student, postdoc programs and initiatives help boost diversity in student pipeline

- Hybrid student program planned for 2021

- Summer Schools are a unique pipeline with targeted recruiting: nine summer schools planned for 2021

- More opportunity to increase diversity in postdoc program, a key staff pipeline

- $75 \%$ of new hires in past year are from New Mexico

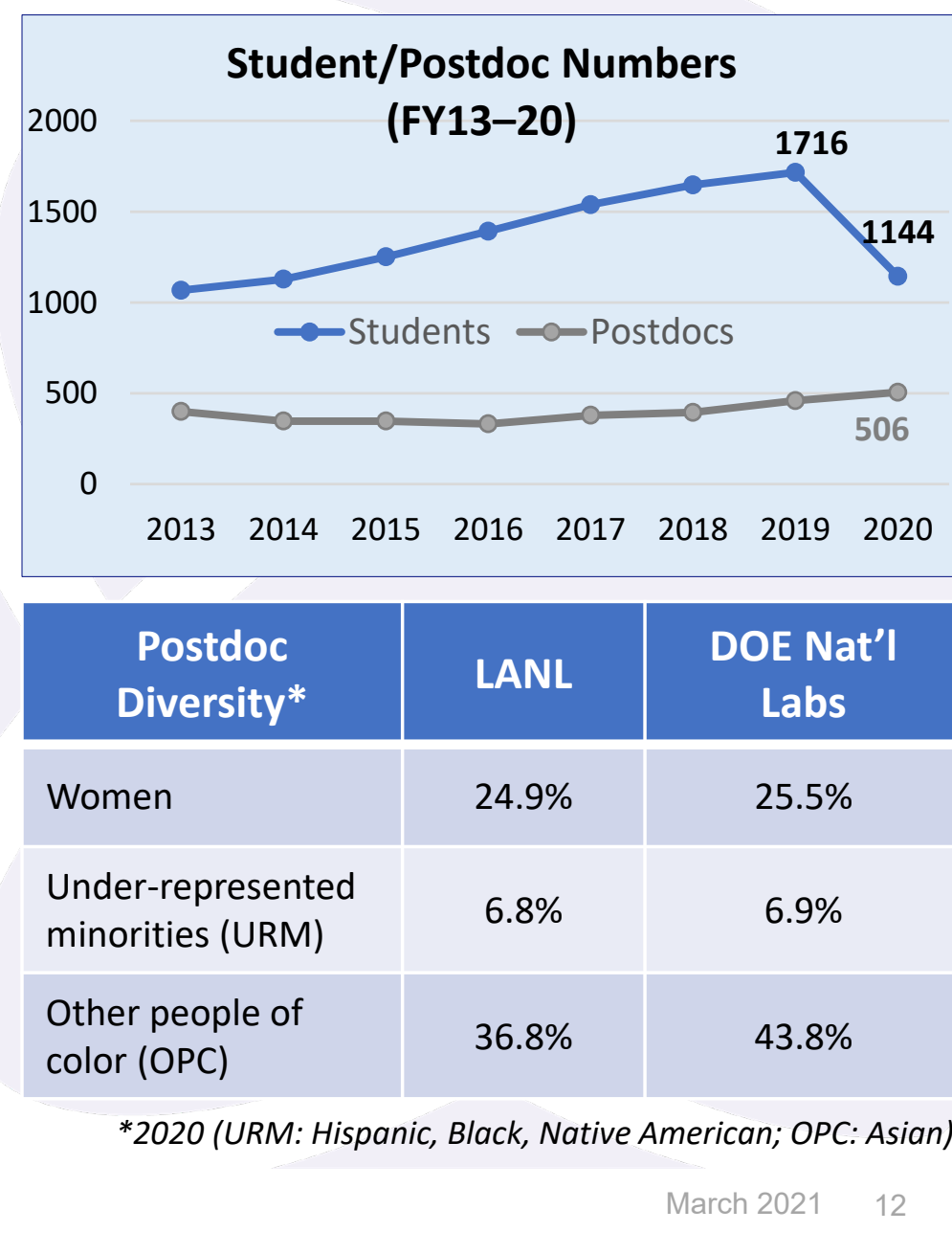




\section{LDRD, invested through the pillars, is an important mechanism to ensure capability health}

\section{Baseline LDRD Program}

FY21 Budget: \$165M*

Exploratory Research $25 \%$

Strengthen capabilities via discipline focus

Directed Research $42 \%$

Explore mission solutions via interdisciplinary teams

Reserve (*As of $7 / 20)$ (unencumbered) $8 \%$

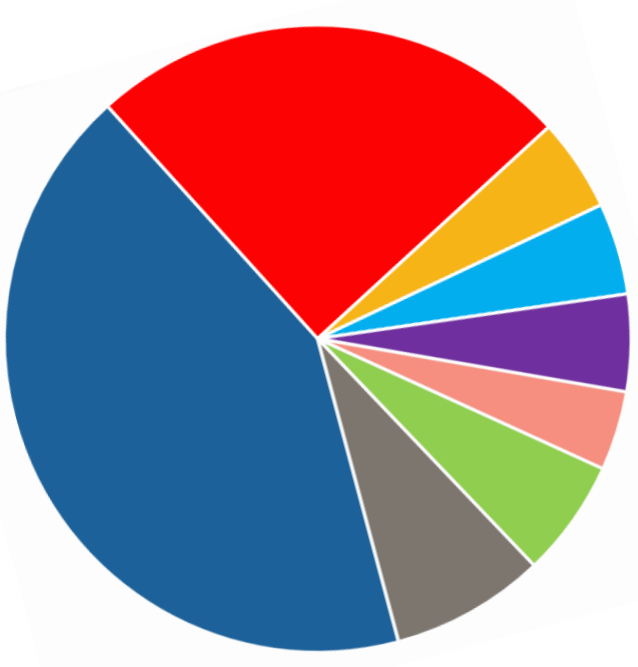

Early Career Research $5 \%$

Develop next-generation technical leadership

Postdoctoral R\&D $5 \%$

Support top-quality talent

Mission Foundations $5 \%$

Translate discovery into innovative solutions

Centers

$4 \%$

Advance rapid-turnaround ideas

Director's Initiative $6 \%$

Bolster growth areas determined by Lab leadership

We invest LDRD to foster mission agility, technical vitality, and workforce development 


\section{Los Alamos delivers national security mission solutions}

- By applying multidisciplinary science, technology \& engineering capabilities, in unique experimental, computational, and nuclear facilities

- With an agile, responsive, and innovative workforce

- Dedicated to addressing complex national security issues and the world's most difficult challenges

- And partnering with like-minded colleagues for mission success
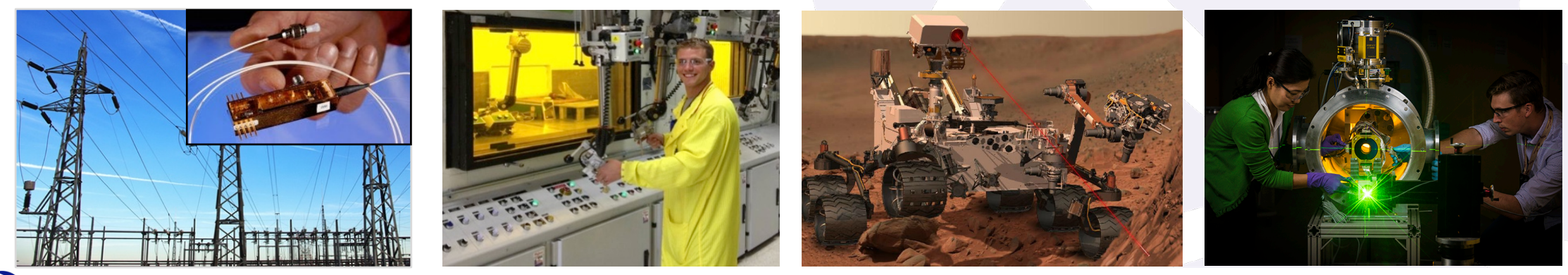


\section{Slide Options}




\section{Our national security mission is broad and important - and motivates and is enabled by ST\&E discovery}

\section{Ensure the safety, reliability, and performance of the U.S nuclear stockpile}

- Physics \& Design

- Engineering \& Weaponization

- Production

Preventing and countering efforts of proliferants to acquire, develop or disseminate materials and expertise necessary for nuclear weapons

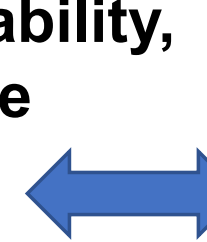

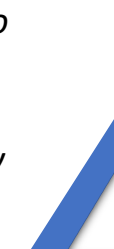

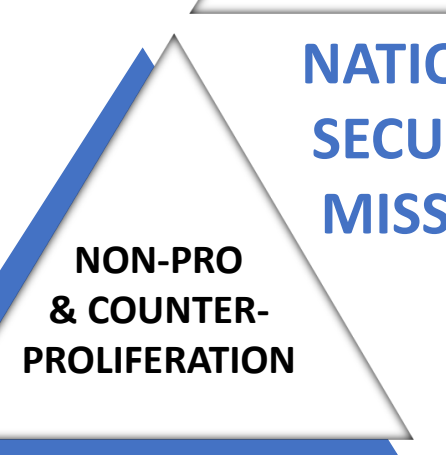

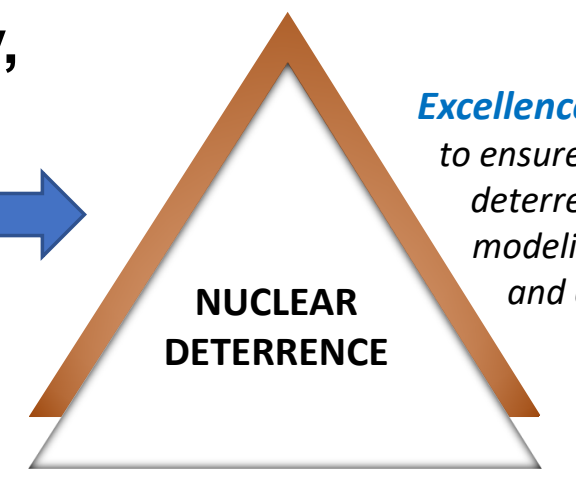

Excellence in nuclear security to ensure the nation's nuclear deterrent through theory, modeling and simulation, and experimentation

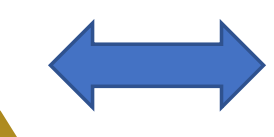

\section{Energy security}

- Sustainable Nuclear Energy

- Resilient Materials

- Complexity in Energy Systems 


\section{Laboratory Agenda ensures simultaneous excellence}

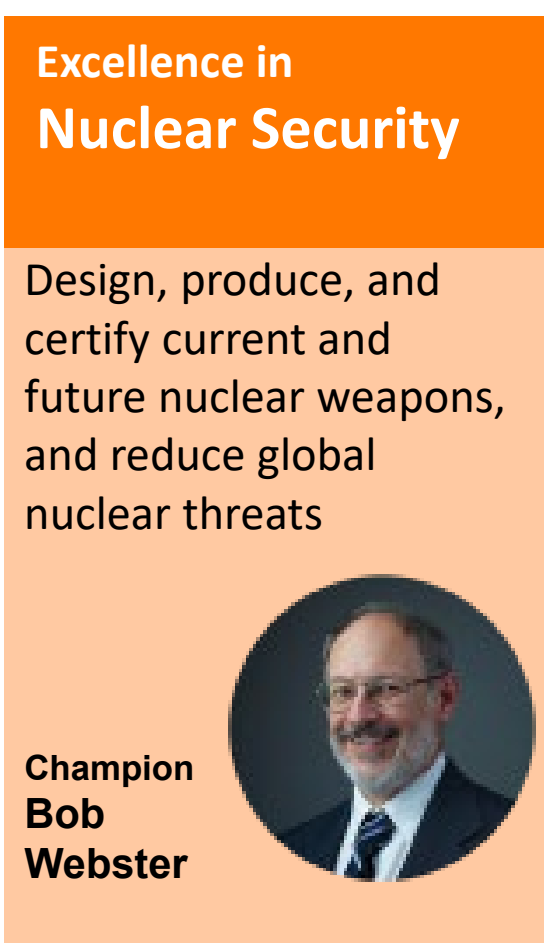

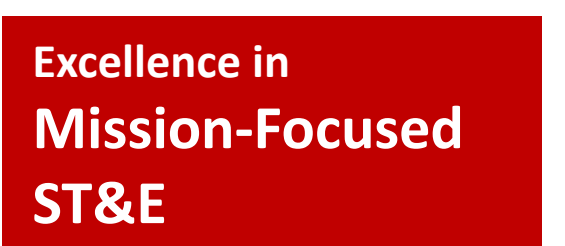

Deliver scientific discovery and technical breakthroughs that support DOE and NNSA missions

Champion

John

Sarrao

\section{Excellence in \\ Mission \\ Operations}

Execute sustained operations that are reliable and responsive to mission needs

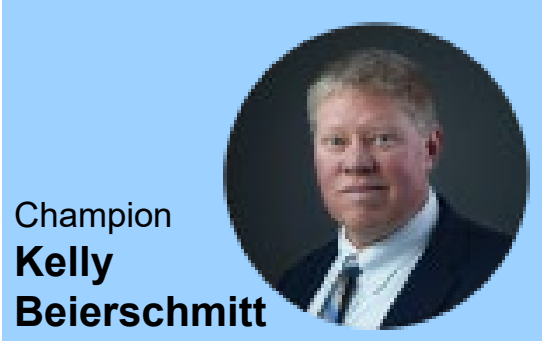

Excellence in Community Relations

Sustain and enhance LANL's partnership with the community across the Northern New Mexico region

Champion Frances Chadwick

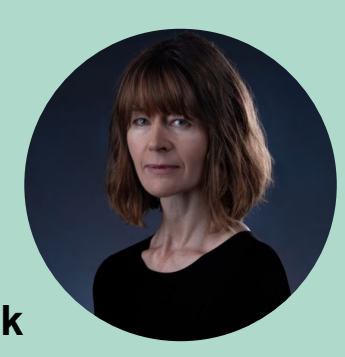

